\title{
JUVENTUDE E MORTE: REPRESENTAÇÕES NA CONTEMPORANEIDADE
}

\author{
Andrea Silvana Rossi*
}

\begin{abstract}
RESUMO
O presente artigo objetiva relacionar as representações sociais da juventude e da morte jovem com as características da época contemporânea. Para tanto, discorre sobre algumas das modificações nos costumes de vida ou organizações sociais, que vêm se organizando estruturalmente desde o Renascimento, cujas configurações vão assumindo contornos mais nítidos na atualidade. No que diz respeito ao ser jovem, observa-se uma valorização e, das questões referentes à morte, um distanciamento ou evitação. Com isso, a morte de jovens configura-se como uma contradição, um paradoxo difícil de ser aceito.

Palavras-chave: juventude, morte, representações.
\end{abstract}

\begin{abstract}
The objective of the article is to study the relation between the social representations of the younth and the young death with the caracteristics of the Contemporanean age. For this, it shows some of the changes in the life's style or social organizations, those have been organized structually since the Modern Age, which representations have been more clear actually. About been young, what is observed is a value and, about death, a distantation or evitation. With this, the death of young people shows a contradiction, a hard paradox to be accept.
\end{abstract}

Key-words: younth, death, representations.

* Mestranda do Curso de História da UFPR e psicóloga clínica do Hospital Erasto Gaertner. 


\section{O ideal de juventude}

Descreve-se a contemporaneidade como responsável por uma série de transformações que afetam os mais variados aspectos da vida humana. Trata-se de um "mundo desenfreado", em que as práticas sociais mudam rápida e profundamente, desencadeando um corte com os modos de comportamento preexistentes. ${ }^{1}$ Apesar desse dinamismo ser mais nítido e linear no que se refere à tecnologia, ele permeia todas as esferas sociais. Nelas, porém, a modificação não é caminho de um sentido só. Caracteriza-se por uma descontinuidade em relação à gama de culturas e modos de vida prémodernos, ou seja, as normas e os valores das sociedades tradicionais são modificados; conseqüentemente, não se valorizam mais os arranjos sociais coletivamente assumidos. Na modernidade, prolifera uma variedade de relações, que determina diversidade de estilos de vida e inumeras possibilidades de combinações.

Os modos de vida colocados em ação pela modernidade nos livraram, de uma forma bastante inédita de todos os tipos tradicionais de ordem social (...) No plano da extensão, elas serviram para estabelecer formas de interconexão social que cobrem o globo; em termos de intensidade, elas vieram a alterar algumas das mais íntimas e pessoais características de nossa existência cotidiana. ${ }^{2}$

Nas sociedades tradicionais existe um ordenamento, o indivíduo apóia-se nas tradições e nas estruturas preexistentes, há a valorização do passado porque este perpetua a experiência de gerações. ${ }^{3}$ Na modernidade, em contra partida, revela-se uma descontinuidade com o passado e há modificações na maneira de entender o mundo, as ações e os homens, ocorren-

1 GIDDENS, A. Modernidade e identidade pessoal. 2. ed. Oeiras: Celta, 1997. p. 14.

2 GIDDENS, A. As conseqüências da modernidade. São Paulo: Editora Universidade Estadual Paulista, 1991. p. 14.

3 HALL, S. A identidade cultural na pós-modernidade. Rio de Janeiro: DP\&A, 2000. p. 25. 
do um afrouxamento das linhas que conduzem a geração mais jovem à mais velha. O mundo moderno põe em circulação novos elementos culturais, favorecendo a emergência incessante de novas significações e combinações na sociabilidade. Conseqüentemente, não ocorre a manutenção dos papéis e funções sociais e familiares tradicionais, pois eles são continuamente recriados.

Esse quadro determina transformações profundas no funcionamento familiar. Do século XVI, ao XX ocorre uma inclinação para a família nuclear, isolada, e para uma maior autonomia pessoal, assim como a ênfase nos laços afetivos entre os cônjuges e seus descendentes. Mas estes não têm percorrido um caminho estável. Nas atitudes sexuais e relações de poder intrafamiliares podem-se observar grandes e misteriosas oscilações, que variam da repressão à permissividade e vice-versa. A última corrente de permissividade começou lentamente nas classes médias da década de 1870 e gradativamente estendeu-se por todos os setores da população ate os dias atuais. ${ }^{4}$ Em função dessa realidade, inicia-se a diminuição da influência da família na escolha da profissão, assim como na do parceiro. O poder patriarcal começa a desgastar-se e a família baseada na autoridade do pai-chefe vai sofrendo modificações que, com o tempo, retiram do pai o estatuto de autoridade ordenadora.

Em decorrência desse declínio da função paterna, os pais apresentam dificuldades de impor obrigações ou mesmo de submeter o jovem a situações que lembrem seu próprio passado. As probabilidades de que os filhos adolescentes venham a ter as mesmas opiniões que os pais são significativamente mais fracas hoje do que antes. O sacrifício de si em função dos desejos dos pais não tem mais a legitimidade social de outrora e os jovens podem buscar outros meios de lidar com o mundo, diferentes e mais relevantes do que os apresentados pelos progenitores. A nova geração não carrega sonhos de igualdade social, mas de interesses pessoais.

Com efeito, a modernidade é tributária à valorização dos desejos de cada indivíduo, do seu bem-estar, da sua liberdade, do interesse próprio. ${ }^{5}$

4 STONE, L. Familia, sexo y matrimonio en Inglaterra 1500-1800. México: Fondo de Cultura Económica, 1989. p. 341.

5 LIPOVETSKY, G. A era do vazio. Ensaios sobre o individualismo contemporâneo. Lisboa: Relógio d'Agua, 1989. p. 19. 


\begin{abstract}
A concepção do homem como indivíduo implica o reconhecimento de uma ampla liberdade de escolha. Alguns dos valores, em vez de emanarem da sociedade, serão determinados pelo indivíduo para seu próprio uso. Por outras palavras, o indivíduo como valor (social) exige que a sociedade lhe delegue uma parte da sua capacidade de fixar os valores. ${ }^{6}$
\end{abstract}

Ocorre, então, um processo de personalização, em que o ser humano passa a ser reconhecido na sua singularidade. Trata-se do culto ao ser individual, ou seja, da "revolução individualista", em que um sujeito igual a outro qualquer é percebido e se percebe como fim último, concebe-se isoladamente e conquista o direito à livre disposição de si próprio. ${ }^{7}$ Iniciado na Renascença, esse valor foi afirmando-se gradativamente e atinge o seu ápice principalmente influenciado pela liberação social e pessoal da juventude na década de 1960, que, a partir de manifestações políticas, do uso das drogas e da liberação sexual, procurava despedaçar o poder da lei, do Estado, dos pais e das convenções. O mundo passa a ser formado por indivíduos a procura da satisfação de desejos isolados, incluindo aqueles até então mal vistos, mas autorizados por todos os que deles usufruíam. ${ }^{8}$

O mundo moderno, desde a sua gênese, instala uma cultura centrada na realização do eu, na espontaneidade e na fruição, determinando, com isso, o culto ao consumo, que surge como algo que possibilitaria satisfazer imediatamente os desejos. A moral tradicional, parcimoniosa, gregária e repressora, chamada por alguns de puritana, cede gradativamente lugar a valores hedonistas que encorajam a gastar, a gozar da vida, a obedecer aos impulsos. O hedonismo se impõe como valor último e legitimação do capitalismo. ${ }^{9}$ Trata-se da sedução da "sociedade de consumo", através da qual o marketing promete suprir a falta e trazer a felicidade, quase a volta ao "paraíso". Pode-se dizer que a mercadoria se transforma num fetiche e retira da multidão o mesmo efeito que os viciados manifestam sob a influência da

6 DUMONT, L. O Individualismo. Uma perspectiva antropológica de ideologia moderna. Rio de Janeiro: Rocco, 1985. p. 269.

7 LIPOVETSKY, op. cit., p. 87.

8 HOBSBAWM, E. Era dos extremos: o breve século XX. São Paulo: Cia. das Letras, 1995.

Capítulo 11.

9 Ibid., p. 81. 
droga: "Se a mercadoria tivesse uma alma, esta seria a mais plena de empatia já encontrada no reino das almas, pois deveria procurar em cada um o comprador a cuja mão e a cuja morada se ajustar." 10

Nessa mesma linha, a cultura ocidental vem sendo caracterizada pelo "canibalismo mercantil", no qual mesmo o homem e o seu corpo se tornam mercadorias numa sociedade consumista, cujo maior interesse é manter o circuito de produção e consumo. ${ }^{11}$ Esta realidade pode ser observada contemporaneamente no tráfico de drogas, de crianças, de mulheres, de órgãos e na contínua oferta de oportunidades para rejuvenescer o corpo. A valorização do corpo jovem não é, porém, uma especificidade da modernidade. A ideologia e a estética corporal cultuada pelos antigos atravessaram toda a Idade Média, constituindo-se numa espécie de ideologia que gerou a preocupação com a conservação do corpo delgado, ágil, saudável, viçoso e belo, mediante receitas e regimes de saúde. ${ }^{12}$ Contudo, é somente na modernidade que o aprimoramento da ciência permite investir capital, tecnologia e consumo nesse ideal. Ideal concretizado nas cirurgias plásticas, implante de cabelos, academias de ginástica, cosméticos, spas, salões de beleza.

O imperativo "ser jovem", expresso pelas idéias de juventude de corpo e de espírito, gera nos indivíduos o desejo de efetuar uma corrida contra o tempo para não envelhecer. Muitas campanhas publicitárias apropriam-se desta "imagem narcisista" e convidam a consumir a juvenilidade por meio dos produtos ofertados. A juventude e o corpo jovem transformam-se em moda, pronta para ser consumida. ${ }^{13}$

Programas de televisão e rádio, revistas e jornais que querem alcançar um público jovem primam por uma forma não linear, aparentemente não lógica, não usual, sugerindo que o jovem subverte a ordem das coisas. Ora, tanto quanto as diagramações

10 BENJAMIN, W. Charles Baudelaire: um lírico no auge do capitalismo. São Paulo: Brasiliense, 1989. p. 38. (Obras escolhidas, v. 3).

11 ZIEGLER, J. Os vivos e a morte. Rio de Janeiro: Zahar, 1975.

12 PASTOUREAU, M. Os emblemas da juventude: atributos e representações dos jovens na idade medieval. In: LEVI, G.; SCHMITT, J. (Org.). História dos jovens: da antigüidade à era moderna. São Paulo: Cia. das Letras, 1996. p. 257.

13 SILVA, A. Juventude de papel: representação juvenil na impressa contemporânea. Maringá: Eduem, 1999. p. 101. 
e apresentações tradicionais, essa deformação, essa descontinuidade, quebra do visual não comum, tornou-se um modelo ordenado. ${ }^{14}$

A modernização dos costumes, então, afirma o inovar como supremo valor, o novo é valorizado em detrimento do velho, pois é diferente e exclusivo; conseqüentemente, ser moderno é ter sempre novas idéias, assumir reiteradamente novos valores e subverter o estabelecido. Enfim, comportar-se constantemente como um jovem. Essa imagem manifesta a influência da grande transformação cultural que se iniciara na década de 1960 e da qual a juventude foi a principal protagonista. Época conhecida como a da revolução estudantil por excelência, também deixa a marca de um jovem consciente de si mesmo, produtor e produto de uma cultura jovem global.

Nesse novo mundo, criam-se padrões a serem imitados, entre estes, o ideal de juventude absolutamente positivo. O jovem torna-se um representante e um modelo a ser seguido, mas, para isso, é convidado a consumir produtos materiais e espirituais que visam à concretização e à permanência de valores da sua condição. Os elementos dessa cultura tornam-se mercadorias disponibilizadas a todos os segmentos etários. O que importa não é só o que vai ser consumido, mas como o será. São produções da "indústria cultural", que cria um repertório preestabelecido de escolhas, simulando a diversidade. Nesta, o indivíduo transforma-se em consumidor e produtor de sua existência. ${ }^{15}$ Nessa sociedade que reinventa e recria incessantemente, verifica-se a busca de perenizar não só o corpo jovem, mas o estado de juventude. Essa incansável procura pelo sonho da eterna juventude ameaça aprisionar os jovens com sua cultura industrial e missionária e, ao mesmo tempo, marca a vida dos adultos, consistindo um triste ideal, já que se trata de uma utopia de quem tem a juventude pelas costas. ${ }^{16} \mathrm{Na}$ tentativa de incorporar esse ideal, muitos adultos são surpreendidos imitando o estilo de vida dos jovens, o jeito de se vestir, de comer, de relacionar-

14 SILVA, op. cit., p. 68.

15 SALLAS, A. L. (Org.). Os jovens de Curitiba: desencantos e esperanças, juventude, violência e cidadania. Brasília: Unesco, 1999. p. 213.

16 SCHINDLER, N. Os tutores da desordem: rituais da cultura juvenil nos primórdios da era moderna. In: LEVI; SCHMITT, op. cit., p. 311. 
se com o sexo oposto. O sujeito adolescente depara-se, então, com adultos que, antes de estarem seguros e satisfeitos com o seu lugar no mundo, mostram fragilidade, insegurança e desconforto, ou seja,

\begin{abstract}
Um sujeito que ao escutar os mais velhos, os "adultos", escuta um repertório de queixas, sofrimento, escolhas mal feitas e exemplos do que não fazer. Um sujeito que, ao olhar para este "adulto", vê insegurança e imitação do seu estilo de vida. Enfim, um sujeito adolescente que, ao aproximar-se do mundo adulto, se depara com um adulto fragilizado, muitas vezes aberto para ouvir, receptivo para receber, mas indeciso na hora de contribuir e opinar. ${ }^{17}$
\end{abstract}

Diante dessa realidade apresentada pelos mais velhos, o próprio jovem pode encontrar pouco interessante a idéia de amadurecer e ingressar na vida adulta, preferindo, muitas vezes, protelar as suas decisões o máximo possível. Esse quadro pode desencadear uma ampliação do período específico da juventude, compreendido como uma fase precisa da vida, bem diferenciada tanto da infância quanto da maturidade e que finalizaria com o casamento, a casa própria e a aquisição de responsabilidades. O fim desse processo vem sendo gradativamente adiado. Um dos responsáveis por essa renúncia temporária da vida adulta é o investimento na "formação", período que geralmente dura anos e livra muitos jovens da necessidade de se manter ou mesmo assumir outras responsabilidades da vida adulta. ${ }^{18}$

Esse período dedicado exclusivamente à formação do jovem surge desde as primeiras fases da modernização dos costumes articulado às exigências das transformações operadas em todos os setores (sociais, econômicos e políticos) da sociedade e pode ser considerado uma "moratória social". ${ }^{19}$ Termo utilizado para definir o período em que admite-se que os

17 ESPIG, A. S. Quem não quer ser adolescente. In: CONGRESSO INTERNACIONAL DE PSICANÁLISE E SUAS CONEXÕES. O ADOLESCENTE E A MODERNIDADE, 1999, Rio de Janeiro. Anais... Rio de Janeiro: Cia. de Freud, 1999. p. 172.

18 Em Curitiba, $78 \%$ dos jovens entre 14 e 20 anos são estudantes, os $22 \%$ que não estudam referem ser os principais motivos o trabalho, no caso dos homens, e filhos, gravidez ou casamento, no caso das mulheres. SALLAS, op. cit., capítulo 5.

19 SCHINDLER, op. cit., p. 271 
jovens se dediquem somente ao estudo durante um largo período de tempo. Essa fase vai se tornando cada vez maior, assim como o ingresso ao mundo dos adultos foi ficando mais distante. Etapa de passagem, sem responsabilidades ou compromissos, passa a ser reconhecida socialmente como um ideal a ser atingido ou no qual se deve permanecer, um ideal que constrói um mito, o mito da juventude. Assim, estende-se a juventude, a idade da inovação, do corpo conservado, a chamada "primavera da vida".

Contudo, o significado atribuído à juventude por quem olha de fora pode não ser o mesmo daquele vivenciado pelo sujeito adolescente. Este, na atualidade, geralmente não se reconhece frente ao jovem retratado pelos meios de comunicação, ou seja, aquele que não trabalha, não estuda, passa o tempo todo se divertindo, sem compromissos e que pode fazer tudo o que quiser. Ao contrário disso, os jovens referem preocupações com o dia de amanhã e se sentem responsáveis pelo seu futuro. ${ }^{20}$ Inclusive os jovens que não trabalham e viabilizam o estudo por intermédio da família são responsabilizados pelo desempenho nos estudos, sucesso no ingresso ao mundo do trabalho e conseqüente emancipação da família. Ao mesmo tempo, a família pode converter a relação de dependência num compromisso de retribuição, uma vez que sustenta o jovem.

Quando isto acontece, ela (família) como que abdica da responsabilidade exclusiva de socializar o jovem, subordinandoo às dimensões e aos valores restritos da situação familiar. Através das relações de manutenção, a família impede que os vínculos que o jovem com ela mantém sejam esterilizados ou mesmo subvertidos. ${ }^{21}$

Trata-se de uma troca de dádivas, ou seja, "não existe a dádiva gratuita (...) o ato inicial é um atentado à liberdade de quem o recebe. Ele contém uma ameaça: obriga à retribuição, e a retribuição com acréscimo; isto é, cria obrigações, é um modo de reter criando devedores." ${ }^{22}$

20 SALLAS, op. cit., capítulo 6.

21 FORACCHI, M. O estudante e a transformação da sociedade brasileira. São Paulo: Nacional, 1965. p. 126.

22 BOURDIEU, P. Razões práticas: sobre a teoria da ação. Campinas: Papirus, 1996. p. 8. 
Pode-se então falar de duas representações da juventude, uma daquele que é de fato jovem e outra daqueles que já o foram, que se distanciaram e olham para o passado com nostalgia. Mas, independente dessas visões, é fato que, assim como a sociedade atual, os jovens mudam rapidamente, o tempo se encarrega de transformá-los, amadurecê-los e lhes mostrar que não se pode parar o tempo. A degradação é inevitável, determinando assim o envelhecimento e a morte.

\section{A morte "selvagem"}

"Selvagem" é o termo utilizado por P. Ariès para falar da característica da morte na atualidade. $\mathrm{O}$ autor acredita que as representações da morte mantiveram a sua estrutura praticamente intacta durante um período de longa duração, que vai desde a Idade Média até o século XIX. E este último (século XIX) caracteriza-se por fortes mudanças no mundo dos vivos, o que influencia o entendimento e o relacionamento da morte e do morrer.

Entre as transformações do último século, podemos destacar o significativo aumento da expectativa de vida na sociedade, ou seja, nesse período, a média de vida duplicou. ${ }^{23}$ Entre os responsáveis por essa alteração encontram-se a elevação dos níveis de higiene e recursos tecnológicos, aumento da oferta de alimentos. Essas modificações podem se relacionar ao desenvolvimento do bio-poder, que vem se alastrando desde o século XVIII, quando o Estado começou a se preocupar com a vida do homem e não mais com o território e as guerras. $\mathrm{O}$ homem se tornou, ao mesmo tempo, objeto e sujeito do saber e, sendo objeto de vários saberes, é também atravessado por estes.

23 No Brasil, no inicio do século XX, a esperança de vida ao nascer era de menos de 35 anos, em 1999 é de 68,4 anos. FUNDAÇÃO INSTITUTO BRASILEIRO DE GEOGRAFIA E ESTATÍSTICA IBGE. Anuário estatístico do Brasil. Rio de Janeiro, 1997/9. 
A velha potência da morte em que se simbolizava o poder soberano é agora, cuidadosamente, recoberta pela administração dos corpos e pela gestão calculista da vida. Desenvolvimento rápido, no decorrer da época clássica, das disciplinas diversas - escolas, colégios, casernas, ateliês; aparecimento, também, no terreno das práticas políticas e observações econômicas, dos problemas de natalidade, longevidade, saúde pública, habitação e migração; explosão, portanto, de técnicas diversas e numerosas para obterem a sujeição dos corpos e o controle das populações. Abre-se assim a era de um "bio-poder". ${ }^{24}$

Dentre os saberes sobre o homem, o avanço científico, mais especificamente da medicina, exerce importante influência no aumento da expectativa de vida, uma vez que oferece novas drogas e técnicas cirúrgicas para adiar o fim. Existe sempre mais um remédio a ser ministrado, trata-se da medicalização, uma das características da morte na atualidade. Diferente da morte domada da sociedade tradicional, entendida como um destino comum e coletivo a todos os homens e mais comumente aceita e vivida sem medos. ${ }^{25}$ As características contemporâneas fazem com que o quarto do moribundo passe a ser o do hospital e, ao mesmo tempo, quem sabe do momento da sua morte é o médico, ou seja, a personalização do saber científico. "Até o século XX o médico era um simples figurante no 'teatro da morte'. No início do atual século, os dois já aparecem em luta e, atualmente, é impossível falarmos de morte sem falarmos no médico, que se tornou o principal personagem nesta peça." 26

A morte que, ate há pouco tempo, ocorria conforme a natureza, vem sofrendo várias transformações e recentemente passa a acontecer principalmente "sob boas condições de laboratório". As velhas causas da morte baseadas notadamente no trinômio "peste, fome, guerra", que deixavam a vida insegura e breve, foram gradativamente substituídas pelos males prolongados, crônicos e incuráveis da atualidade, característicos de idades mais avançadas da vida, que aumentam a duração do processo de agonia na espera da morte. A longevidade das pessoas dos dias atuais, desencadeia essa

24 FOUCAULT, M. História da sexualidade. Rio de Janiero: Graal, 1977. p. 131.

25 ARIÈS, P. O homem diante da morte. Rio de Janeiro: F. Alves, 1982.

26 ZAIDHAFT, S. Morte e formação médica. Rio de Janeiro: F. Alves, 1990. p. 61. 
transformação do motivo e das características do morrer contemporâneo. ${ }^{27}$ Esse processo transformou-se num lento e doloroso apagar-se, um terrível morre-não-morre, e é justamente isso que tanto se teme na atualidade: terminar os dias numa espera prolongada pela morte salvadora. Os avanços da ciência são responsáveis pela morte 'medicalizada' e distante, que é também uma morte longa e temida.

Justamente por ser assustadora, a morte da sociedade ocidental vem desencadeando como resposta mais comum ao seu confronto a evitação e/ou negação: não ver a realidade para se defender da angústia, pois praticamente não se sabe como lidar com a finitude. Isso se deve ao fato de que "no fundo ninguém crê em sua própria morte, ou, dizendo a mesma coisa de outra maneira, que no inconsciente cada um de nós está convencido de sua própria imortalidade." ${ }^{28}$ Trata-se de uma sociedade privada do confronto com a própria finitude, que já não faz uma pausa com a morte de um dos seus membros, isso não lhe afeta a continuidade. Tudo se passa na cidade como se ninguém morresse mais, é a "máscara da morte", onde tudo é realizado para que os vivos nada percebam. O corpo é transportado, o cortejo atravessa a cidade se misturando ao tráfego, mas os seus ruídos mascaram o terror. Num recinto reservado o recebem, o arrumam, vestem com as melhores roupas, o maquiam, disfarçam a palidez do cadáver. Em poucas horas a sua presença é apagada no crematório, na sepultura, sob a terra, coberto por lindos jardins. Logo, a lembrança é imobilizada. ${ }^{29}$

A morte precisa ser mascarada porque é assustadora e, ao mesmo tempo, produz a sensação de estranheza. É estranha porque o sujeito não se reconhece nela, já que a morte implica a destruição do ego, o "des-ser", deixar de existir. O "estranho" é algo que é desconhecido, porém familiar, é aquilo que deveria ter permanecido oculto mas veio à luz. ${ }^{30}$ Ou seja, sabese da existência da morte, mas procura-se não saber; ela faz parte do ser humano, mas fica escondida no mais profundo do seu ser, difícil de encontrar. Justamente por isso é um assunto pouco falado e quando abordado,

27 IMHOF, A. Demografia histórica. In: NEVES, A. A. A nova historiografia alemã. Porto Alegre: UFRGS / Instituto Goethe / Instituto Cultural Brasileiro-Alemão, 1987. p. 107.

28 FREUD, S. Reflexões para os tempos de guerra e morte. Rio de Janeiro: Imago, 1974. (Obras Completas).

29 ZIEGLER, op. cit., p. 142.

30 FREUD, S. O estranho. Rio de Janeiro: Imago, 1974. p. 275-314. (Obras Completas). 
muitas vezes, é feito por chistes ou meias palavras, o que denuncia ser algo não aceito socialmente, um tabu. ${ }^{31}$

A morte, estranha e temida, produz uma falta de palavras, pois é real, não podendo ser simbolizada. Por isso ocorre um afastamento do assunto morte, caracterizando um "silêncio voluntário", em que os homens se calam sobre a sua finitude. Esta deixa de ser falada, escutada ou lembrada. É a cadeia que emudece a sociedade da atualidade diante da morte e que faz com que, muitas vezes, se morra sem poder se comunicar, na solidão dos sentimentos. ${ }^{32}$ Nesse caso, o fim não pode mais ser considerado um fenômeno natural, uma etapa da vida, como aconteceu mais freqüentemente em outros momentos da História, quando a morte era "domada" e o moribundo podia se preparar para recebê-la. A "boa morte" do passado, aquela que podia ser percebida, falada e possibilitava um preparo, é justamente a morte temida dos nossos dias. ${ }^{33}$ Por isso é quase consenso, entre os profissionais da saúde, o adiamento do momento de avisar a família e, mais ainda, o doente da proximidade da sua morte, e "quando a morte chega, ela é considerada um acidente, um sinal de impotência ou de imperícia que é preciso esquecer". ${ }^{34}$ A idéia da morte precisa ser afastada, esquecida, porque remete à limitação, à falta, ao fato de que o ser humano não pode tudo. É justamente porque aponta a falta que desencadeia o desejo de vencê-la, dominá-la, que leva o ser humano a estabelecer uma guerra com a morte, transformando-a em inimiga, "selvagem"; vendo-se totalmente impotente diante dela, contradiz o ideal da atualidade de solução racional.

Esse ideal deve-se ao fato de que, na cultura contemporânea, freqüentemente ocorre um processo de racionalização das visões de mundo e é a partir deste que se tenta dar algumas respostas para a questão da morte. Por exemplo, pela crença de que finalmente se dominou a Natureza; de que a ciência progredirá a ponto de fornecer a felicidade para todos; pela

31 A palavra tabu é de origem polinésia e significa, por um lado, "sagrado", "consagrado", e, por outro, "perigoso", "proibido", "impuro", ou seja, é um termo que traz em si algo de inabordável, proibido e restrito no seu uso. Freud fala que a nossa acepção de "temor sagrado" muitas vezes pode coincidir em significado com tabu. FREUD, S. Totem e tabu. Rio de Janeiro: Imago, 1974. p. 37. (Obras Completas).

32 VOVELLE, M. A história dos homens no espelho da morte. In : BRAET, H.; VERBEKE, W. A morte na Idade Média. São Paulo: Edusp, 1996. p. 18.

33 ARIÈS, P. O homem diante da morte. Rio de Janeiro: F. Alves, 1982.

34 Ibid., p. 640. 
crença na "a-mortalidade" do homem. ${ }^{35}$ São mitos que a sociedade de forma geral vem utilizando para acreditar que a morte foi vencida.

A influência do pensamento racional desencadeia a dissolução das visões de mundo tradicionais, especialmente da religião. Essa ideologia produz o desencantamento do mundo, afirmando que não há nada além da matéria; a morte é o fim de tudo. Com isso, vem contradizer as crenças religiosas e desencadeia um processo de dessacralização da sociedade e dos lugares da morte. Um novo "culto aos mortos" ${ }^{36}$ preenche o espaço vazio deixado pela desagregação das formas religiosas estabelecidas. Nesta linha de pensamento, aconteceria uma desvalorização daquilo que é espiritual, das questões referentes à alma. ${ }^{37}$ Contudo, essa divisão em dois campos diferentes - por um lado, o do conhecimento, da ciência, e, por outro, o das crenças e idéias religiosas - exige alguns cuidados no seu entendimento. Os limites que separam o racional do irracional não são tão claros, e o que geralmente se observa é uma mistura das duas formas de pensamento.

A dessacralização do mundo e das relações sociais é descrita como um traço que há séculos vem se afirmando. Porém, alguns estudos mostram que ela não acontece em todos os contextos e sociedades da mesma maneira. O homem a-religioso no estado puro, praticamente, não existe, ainda que na mais racional das sociedades modernas. Mesmo aquele que se diz sem religião é descendente do "homo religiosus", constitui-se por oposição a esse predecessor e se esforça por se esvaziar de todo significado transhumano. Com isso, o homem moderno reconhece a si próprio à medida que se liberta e se purifica das superstições dos seus antepassados. Contudo, "não pode abolir definitivamente seu passado, porque ele próprio é produto desse passado. É constituído por uma série de negações e recusas, mas continua ainda a ser assediado pelas realidades que assediou e negou". ${ }^{38}$ Então, o homem contemporâneo mais francamente a-religioso partilharia

35 ZAIDHAFT, op. cit., p. 63.

36 Vovelle refere-se, com esta expressão, à rede de gestos, práticas e rituais coletivos que acompanham a morte.

37 RUANET, S. As razões do Iluminismo. São Paulo: Cia. das letras, 1987. p. 231-240. 1992. p. 164-165.

38 ELIADE, M. O sagrado e o profano. A essência das religiões. São Paulo: Martins Fontes, 
ainda, no mais profundo de seu ser, de um comportamento religiosamente orientado, mesmo tendo perdido a capacidade de viver as formas preconizadas pelas religiões institucionalizadas. ${ }^{39}$ Observa-se que, muitas vezes, o confronto com as modificações físicas (decomposição orgânica) acarretadas pela morte desencadeia nos indivíduos a idéia de um espírito separado do corpo, ou seja, sugere a divisão do indivíduo em corpo e alma. ${ }^{40}$

Dessa maneira seu encadeamento de pensamento corria paralelo ao processo de desintegração que sobrevêm com a morte. Sua persistente lembrança dos mortos tornou-se a base para a suposição de outras formas de existência fornecendo-lhe a concepção de uma vida que continua após a morte aparente. ${ }^{41}$

Se nas sociedades do passado essa relação era explicitada pelos altares dedicados às almas no purgatório e por afrescos nas capelas, a atualidade conta com várias formas de manifestações como, por exemplo, a banalização da morte das histórias em quadrinhos, dos vídeogames, da música rock que nada mais são do que fontes de cultura popular e formas de atingir o imaginário coletivo. Essas manifestações indicam algumas atitudes humanas diante da morte, como a preocupação com a salvação das almas e a crença de que a existência tem uma continuidade após a morte. ${ }^{42}$

Entender a morte como uma passagem de um mundo para outro é uma forma de não ver o fim da existência, pois a morte passa a ser despojada do seu significado de término da vida. Isto pode se observar na relação que se tenta manter entre vivos e mortos mediante contatos espirituais. Nessa noção irracional, o corpo morre, mas a alma continua se comunicando com os vivos, ligado ao nosso mundo. ${ }^{43}$

Então, a mesma sociedade que vem se demarcando com características racionais, também apresenta crença e padrões de comportamento fundamentados em grandes irracionalidades. Por isso, pode-se dizer que a

39 ELIADE, op. cit., p. 171.

40 FREUD, 1974, op. cit., p. 332.

41 Ibid., p. 333.

42 VOVELLE, M. Imagens e imaginário na História. São Paulo: Ática, 1997. p. 45.

43 MATTA, R. A casa e a rua. 5. ed. Rio de Janeiro: Rocco, 1997. p. 141. 
sociedade ocidental não mantém um padrão de comportamento diante da morte. Contrariamente, apresenta uma "morte multiforme", em que racionalidades e irracionalidades influenciam as diferentes respostas dos homens quando diante da sua finitude. Essa ambigüidade é explicada por Soares da seguinte forma:

O que marca a nossa experiência moderna é a variedade, a heterogeneidade, a diferenciação; é a articulação do "tradicional" com o moderno; é a convivência do mágico-real - o irracional - com a racionalização. O desencantamento do mundo entre nós não atingiu a radicalidade de revolução que na Europa teve como objetivo colocar a ciência no lugar até então ocupado por Deus no imaginário das sociedades. Nosso mundo ainda não está totalmente desencantado: o céu não foi totalmente esvaziado de seus símbolos, persistem nele as projeções, embora encontrem-se seriamente mutiladas. ${ }^{44}$

\section{A contradição juventude-morte na atualidade}

A juventude ou a adolescência ocorre no momento em que o indivíduo distancia-se da infância por ser invadido fisiologicamente pelos caracteres sexuais secundários e, ao mesmo tempo, situa-se sociologicamente num lugar aquém do considerado como sendo o do adulto. $\mathrm{O}$ adolescer se dá a alguém quando este se vê convocado, desde seu corpo e desde o olhar de outro, a ser algo diferente do que a criança que foi. ${ }^{45}$ Marca-se, com isso, a emergência de uma mudança, uma modificação do lugar a ser

44 SOARES, M. S. A. (Re)Pensando a modernidade latino-americana. Cadernos de Sociologia, Porto Alegre, v. 1, n. 1, p. 29, maio/jul. 1989.

45 RUFFINO, R. Adolescência: notas em torno de um impasse. Revista da Associação Psicanalítica de Porto Alegre, ano 5, n. 11, p. 41, nov. 1995. 
ocupado pelo jovem que inicia o processo de adolescer. E trata-se de um processo, porque não ocorre a substituição de uma velha estrutura por uma nova e sim a transformação em algo novo que conserva em si o antigo, ou seja, não se trata de uma etapa que inicia e termina em determinado momento da vida (no sentido de delimitação temporal). ${ }^{46}$

Nesse momento, a aparição dos caracteres sexuais secundários e a conseqüente possibilidade da sexualidade genital confrontam o jovem com a morte imaginária. Em decorrência das alterações orgânicas, vivem-se algumas perdas, como a da imagem de si mesmo e da criança ideal, tanto para o adolescente como para os pais; a perda dos pais como sustentação do ideal do eu infantil; a perda do corpo infantil. ${ }^{47}$ Somada a essas perdas, ainda demarca-se uma mudança de posição, pois o jovem é agora capaz da reprodução, o que potencialmente o coloca no lugar de pai e ao seu pai no lugar de avô. Essa diferenciação das gerações possibilita que o pai possa ser visto como limitado e mortal.

\begin{abstract}
$\mathrm{O}$ adolescente descobre em um segundo tempo que este pai, que se parece com ele, é mortal, no real, de uma morte sem causa, e que esta transmissão se ordena como perda.(...) Quando o filho se mede ao pai, o corpo do pai entra em cena, não mais mítico mas tomado em uma cadeia na língua, e da qual o nascimento e a morte são as pontuações reais. ${ }^{48}$
\end{abstract}

São essas questões que demarcam uma primazia da morte ou da contradição vida-morte na estrutura psíquica do adolescente, o que, segundo S. Turbert, "é uma oposição (vida e morte) que aparece como tema central da adolescência, seja porque estes significantes remetem às pulsões freudianas, à progressão-regressão, à integração-desintegração, à síntesedestruição, ao aparecer no mundo-desaparecer dele, ao crescimento-paralisia." 49

46 TUBERT, S. A morte e o imaginário na adolescência. Tradução: P. Vidal. Rio de Janeiro: Cia. de Freud, 1999. Capítulo 1.

47 Ibid., p. 14.

48 RASSIAL, J. Hipóteses sobre adolescência. Revista da Associação Psicanalítica de Porto Alegre, ano 5, n. 11, p. 27, nov. 1995. Publicação interna.

49 TUBERT, op. cit., p. 19. 
A reflexão sobre as peculiaridades do "ser-adolescente" mostra o quanto a morte encontra-se presente nesse momento da vida. Contudo, há uma diferença entre o adolescente fisicamente sadio, que se depara com a morte no registro do imaginário, e aquele que se encontra afetado no próprio corpo por uma doença letal e se confronta com a morte no registro do imaginário e do real ao mesmo tempo. Para este, a morte real pode ser mais uma ou a última de uma série de perdas que, nesse caso, culminaria com a do próprio ser. Seria um "se perder" frente às transformações que o momento de vida lhe impõe, entre elas, a tomada de posição enquanto adulto. Por outro lado, para o social mostraria que sim, é possível morrer jovem, que não há idade para a morte e, conseqüentemente, a juventude e a vida que há nela podem acabar juntas. Muitos ídolos permanecem eternizados na memória por ter morrido jovens, ou seja, por eternizarem a idealização da própria imagem. Essas figuras, vítimas de um estilo de vida fadado à morte precoce, tornaram-se um ideal típico, no que se formou a expressão cultural característica da juventude - o rock. Contraditoriamente, a mesma morte jovem que assusta, pode provocar um fascínio, pois somente assim os homens podem se manter sempre jovens na lembrança daqueles que ficam. Trata-se de uma tentativa de eternizar-se na juventude. ${ }^{50}$

Contudo, terminar os dias na adolescência não é um fascínio de todos. Isso justifica o fato de a atual sociedade tentar eternizar a juventude pelo aperfeiçoamento da ciência, que além de possibilitar uma vida longa, oferece procedimentos técnicos para manter o corpo jovem. Juventude, na cultura de hoje, é sinônimo de vitalidade, saúde, energia e uma expectativa de vida longa. Acredita-se que, quanto mais jovem se for, mais distante do fim se estará. Então, os homens passam a não olhar para a finitude, a negála, a viver como jovens atemporais, como se fossem imortais. Não ver a morte pode fazer acreditar ou, no mínimo, manter viva a fantasia da vida eterna. Mas ninguém quer viver a vida eterna sendo velho, enrugado e limitado pelo peso dos anos. O desejo, então, é de juventude eterna. ${ }^{51}$

A morte de um jovem ou a sua possibilidade contradiz as expectativas da sociedade com relação a essa faixa etária, pois ele é visto como

50 HOBSBAWM, op. cit., p. 318.

51 BROMBERG, M. et al. Vida e morte: laços da existência. São Paulo: Casa do Psicólogo, 1996. 
daqueles que "ainda têm muito pela frente", como concluir os estudos, formar uma família, ser independentes. ${ }^{52}$ Ainda, vem desmontar a imagem do jovem idealizado, aquele que é sinônimo de liberdade, inovação, beleza e satisfação imediata dos desejos. O jovem à beira da morte contradiz as crenças sociais de que a adolescência "pode tudo" e, mais ainda, os ideais decorrentes do pensamento racional. Por isso, é comum observar que o afastamento de uma discussão a respeito da morte aumenta quando a idade do moribundo diminui. Para a sociedade, a morte de um jovem não termina apenas com a sua vida, mas destrói toda a magnitude dos valores a ele atribuídos por ela, entre eles: a imortalidade. Ver um adolescente morrendo viria somente desmontar essa ilusão. Porque a degradação do corpo decorrente das doenças ou do passar dos anos denuncia a verdadeira condição humana, o fim de cada dia, de cada ano, e faz lembrar que o corpo que habitamos é perecível, que a juventude não é eterna. A realidade mostra que a finitude existe e que todo conhecimento científico não é suficiente para derrubá-la.

A modernização dos costumes, com as suas mudanças, racionalidades, individualismos e inovações, traz consigo a valorização da juventude e quer distância da morte, já que quanto mais longe menos pode ser vista. Não ver a finitude permite, também, deixar-se seduzir pela sociedade individualista e de consumo, que afirma constituir o prazer, a felicidade da vida, o que se pode conseguir dando vazão aos impulsos e consumindo. A cultura industrial do Ocidente procura negar a morte em proveito do produtor-consumidor. O apego aos bens materiais e o desejo de conservar tudo que se tem exigem a morte da morte, ou seja, ela não pode ser levada em conta, aceita, e então só pode ser negada, mascarada. Por outro lado, a consciência do destino inevitável de todos os homens, o fim - mesmo que negado -, desencadeia um questionamento e a valorização da vida. Investe-se na existência, em aproveitar a vida e manter-se jovem, porque sabe-se da finitude.

52 MAAKAROUN, M.; SOUZA, R. de et al. Tratado de adolescência: um estudo multidisciplinar. Rio de Janeiro: Cultura Médica, 1991. p. 109. 
Com isso, a morte é ao mesmo tempo reconhecida como valorização da vida e mantida à distância para que não impossibilite o gozo obtido a partir do apego aos bens materiais, às pessoas, aos lugares ocupados, ao corpo jovem.

\begin{abstract}
De fato, toda cultura, no sentido antropológico do termo, é globalmente orientada para a reprodução da vida. Por esta razão, aliás, cada cultura pretende ser uma resposta à questão da morte. Cada uma delas define uma certa relação dos vivos com a morte e com os mortos e procura dar um sentido às diferentes formas que a morte pode tomar, porque ao dar sentido à morte, dá-se um sentido à vida. ${ }^{53}$
\end{abstract}

\title{
Referêncas
}

ARIÈS, P. O homem diante da morte. Rio de Janeiro: F. Alves, 1982.

BENJAMIN, W. Charles Baudelaire: um lírico no auge do capitalismo. São Paulo: Brasiliense, 1989. (Obras escolhidas, v. 3).

BOURDIEU, P. Razões práticas: sobre a teoria da ação. Campinas: Papirus, 1996.

BROMBERG, M.; KOVÁCS, M. et al. Vida e morte: laços da existência. São Paulo: Casa do Psicólogo, 1996.

CUCHE, D. A noção de cultura nas Ciências Sociais. Bauru: Edusc, 1999.

DUMONT, L. O individualismo. Uma perspectiva antropológica de ideologia moderna. Rio de Janeiro: Rocco, 1985.

ELIADE, M. O sagrado e o profano. A essência das religiões. São Paulo: Martins Fontes, 1992.

ESPIG, A. S. Quem não quer ser adolescente. In: CONGRESSO INTERNACIONAL DE PSICANÁLISE E SUAS CONEXÕES. O ADOLESCENTE E A MODERNIDADE, 1999, Rio de Janeiro. Anais... Rio de Janeiro: Cia. de Freud, 1999.

53 CUCHE, D. A noção de cultura nas Ciências Sociais. Bauru: Edusc, 1999. p. 104-105. 
FOUCAULT, M. História da sexualidade. Rio de Janeiro: Graal, 1977.

FORACCHI, M. O estudante e a transformação da sociedade brasileira. São Paulo: Nacional, 1965.

FREUD, S. Reflexões para os tempos de guerra e morte. Rio de Janeiro: Imago, 1974. (Obras Completas).

FREUD, S. O estranho. Rio de Janeiro: Imago, 1974. (Obras Completas).

FREUD, S. Totem e tabu. Rio de Janeiro: Imago, 1974. (Obras Completas).

FUNDAÇÃO INSTITUTO BRASILEIRO DE GEOGRAFIA E ESTATÍSTICA IBGE. Anuário estatístico do Brasil. Rio de Janeiro, 1997/1999.

GIDDENS, A. Modernidade e identidade pessoal. 2. ed. Oeiras: Celta, 1997.

GIDDENS, A. As conseqüências da modernidade. São Paulo: Ed. Universidade Estadual Paulista, 1991.

HALL, S. A identidade cultural na pós-modernidade. Rio de Janeiro: DP\&A, 2000.

HOBSBAWM, E. Era dos extremos: o breve século XX. São Paulo: Cia. das Letras, 1995.

IMHOF, A. Demografia histórica. In: NEVES, A. A. A nova historiografia alemã. Porto Alegre: UFRGS/Instituto Goethe/Instituto Cultural Brasileiro-Alemão, 1987. p. 107.

LIPOVETSKY, G. A era do vazio. Ensaios sobre o individualismo contemporâneo. Lisboa: Relógio d'Água Ltda., 1989.

MAAKAROUN, M.; SOUZA, R. de et al. Tratado de adolescência: um estudo multidisciplinar. Rio de Janeiro: Cultura Médica, 1991.

MATTA, R. A casa e a rua. 5. ed. Rio de Janeiro: Rocco, 1997.

PASTOUREAU, M. Os emblemas da juventude: atributos e representações dos jovens na idade medieval. In: LEVI, G.; SCHMITT, J-C. (Org.). História dos jovens: da antigüidade à era moderna. São Paulo: Cia. das Letras, 1996.

RASSIAL, J-J. Hipóteses sobre adolescência. Revista da Associação Psicanalítica de Porto Alegre, ano 5, n. 11, p. 27, nov. 1995. Publicação interna.

RUANET, S. As razões do Iluminismo. São Paulo: Cia. das letras, 1987.

RUFFINO, R. Adolescência: notas em torno de um impasse. Revista da Associação Psicanalítica de Porto Alegre, ano 5, n. 11, p. 41, nov. 1995. Publicação interna. 
SALLAS, A. L. (Org.). Os jovens de Curitiba: desencantos e esperanças, juventude, violência e cidadania. Brasília: Unesco, 1999.

SCHINDLER, N. Os tutores da desordem: rituais da cultura juvenil nos primórdios da era moderna. In: LEVI, G.; SCHMITT, J-C. (Org.). História dos jovens: da antigüidade à era moderna. São Paulo: Cia. das Letras, 1996.

SHORTER, E. A formação da família moderna. Lisboa: Terramar, 1975.

SILVA, A. C. T. Juventude de papel: representação juvenil na imprensa contemporânea. Maringá: Eduem, 1999.

SOARES, M. S. A. (Re)Pensando a modernidade latino-americana. Cadernos de Sociologia, Porto Alegre, v. 1, n. 1, p. 29, maio/jul. 1989.

STONE, L. Familia, sexo y matrimonio en Inglaterra 1500-1800. México: Fondo de Cultura Económica, 1989.

TUBERT, S. A morte e o imaginário na adolescência. Tradução: P. Vidal. Rio de Janeiro: Cia. de Freud, 1999.

VOVELLE, M. A história dos homens no espelho da morte In: BRAET, H.; VERBEKE, W. (Eds.). A morte na Idade Média. São Paulo: Ed. da Universidade de São Paulo, 1996.

VOVELLE, M. Imagens e imaginário na História. São Paulo: Ática, 1997. p. 45.

ZAIDHAFT, S. Morte e formação médica. Rio de Janeiro: F. Alves, 1990.

ZIEGLER, J. Os vivos e a morte. Rio de Janeiro: Zahar, 1975. 